\title{
UJI KARAKTERISTIK SIFAT MEKANIK BIODEGRADABLE POL YBAG BERBASIS LIMBAH TANAMAN KELAPA SAWIT (TKKS DAN PELEPAH)
}

\section{CAHARACTERISTICS OF MECHANICAL PROPERTIES OF BIODEGRADABLE POLYBAG BASED ON PALM OIL PLANT WASTE (OIL PALM EMPTY BUNCHES AND MIDRIB)}

\author{
Rina Maharany ${ }^{1}$, Ingrid Ovie Yosephine, $\mathrm{S}^{1}$ \\ ${ }^{1}$ Staff Pengajar Program Studi Budidaya Perkebunan, STIPER Agrobisnis Perkebunan Medan. \\ Jalan Willem Iskandar, Pancing Medan Estate 20000 \\ E-mail : rina maharany@stipap.ac.id \\ ABSTRAK
}

Perkebunan sawit telah menjadi perkebunan terbesar di Indonesia, salah satunya terdapat di Provinsi Sumatera Utara. Berdasarkan data Badan Pusat Statistik Provinsi Sumatera Utara menyatakan bahwa luas areal perkebunan kelapa sawit tahun 2016 adalah 417.809 ha dengan produksi TBS mencapai 5.775.631,82 ton, dan akan dihasilkan limbah Tandan Kosong Kelapa Sawit (TKKS) sebesar 23.250 ton/hari pada PKS berkapasitas 50 ton/jam. Material organik baik berupa limbah padat kelapa sawit sangat banyak tersedia dan belum dimanfaatkan secara maksimal. Bahan-bahan tersebut dapat dimanfaatkan sebagai bahan baku pembuatan biodegradable polybag yang dapat digunakan sebagai media tanam untuk bibit tanaman semusim maupun tahunan. Penggunaan biodegradable polybag ini merupakan sebuah solusi dalam mengatasi permasalahan lingkungan seperti akumulasi polybag plastik setelah pembibitan dan menghambat pertumbuhan tanaman akibat pelepasan polybag yang salah. Penelitian ini bertujuan untuk memodifikasi polybag organik yang telah dikembangkan sebelumnya dengan bahan utama limbah TKKS dan pelepah kelapa sawit, serta menentukan komposisi terbaik dari bahan baku tersebut dan melakukan pengujian kualitas sesuai dengan standar mutu kompos SNI.

Kata kunci; Biodegradable Polybag, TKKS, Pelepah, Sifat Mekanik

\section{ABSTRACT}

Oil palm plantations have become the largest plantations in Indonesia, one of which is in North Sumatra Province. Based on data from the Central Statistics Agency of North Sumatra Province, it was stated that the total area of oil palm plantations in 2016 was 417,809 ha with FFB production reaching 5,775,631.82 tonnes, and oil palm Empty Bunches (TKKS) waste would be 23,250 tonnes/day in a PKS with a capacity 50 tons/hour. Organic material in the form of palm oil solid waste is widely available and has not been fully utilized. These materials can be used as raw material for making biodegradable polybags which can be used as a planting medium for seasonal and annual plant seeds. The use of biodegradable polybags is a solution in overcoming environmental problems such as the accumulation of plastic polybags after seeding and inhibiting plant growth due to the wrong release of polybags. This study aims to modify the organic polybag that 
developed previously with main ingredients of EFB waste and oil palm fronds, as well as to determine the best composition of these raw materials and to carry out quality testing by SNI compost quality standards.

Keywords; Biodegradable Polybag, EFB, Pronds, Mechanical Properties

\section{PENDAHULUAN}

Pengolahan 1 (satu) ton tandan buah segar (TBS) kelapa sawit akan menghasilkan limbah berupa tandan kosong kelapa sawit (TKKS) sebanyak $3 \%$ atau $230 \mathrm{~kg}$, limbah cangkang (shell) sebanyak $6,5 \%$ atau $65 \mathrm{~kg}$, lumpur sawit (wet decanter solid) $4 \%$ atau $40 \mathrm{~kg}$, serabut (fiber) 13\% atau $130 \mathrm{~kg}$ serta limbah cair sebanyak 50\%. Diperkirakan limbah padat yang dikeluarkan pabrik kelapa sawit yang berkapasitas 50 ton per jam, yaitu 23.250 ton/hari (Joko et al., 2017).

Penanganan limbah kelapa sawit saat ini belum dilakukan secara optimal dan ekonomis, padahal ketersediaannya melimpah sepanjang tahun. Oleh sebab itu perlu perhatian khusus agar limbah kelapa sawit dapat diolah dan dimanfaatkan sehingga memiliki nilai jual. Salah satu alternatif pemanfaatan yang in telah dilakukan adalah mengolah limbah padat kelapa sawit (TKKS dan pelepah) menjadi biodegradable polybag. Kembali ke alam merupakan istilah yang tepat untuk menggambarkan kondisi ilmu pengetahuan dan teknologi saat ini.

\section{Prospek}

pemakaian

biodegradable polybag yang ramah lingkungan akan semakin diperlukan dan merupakan peluang komoditi yang dapat dipasarkan di tingkat nasional dan internasional, sehingga nantinya perlu dilakukan pengujian kualitas biodegradable polybag berbahan baku limbah padat kelapa sawit. Dengan mengetahui sifat fisik dan mekanika biodegradable polybag, maka akan diketahui kualitasnya sebagai media tanam organik, dan akan dibandingkan dengan standar mutu kompos menurut SNI. Selain itu dapat dibandingkan dengan kualitas dengan kantong tanam berbahan organik lainnya seperti eceng gondok, jerami, dan lain-lain.

\section{METODE PENELITIAN}

Penelitian dilaksanakan di Rumah Kaca Kebun Percobaan Sekolah Tinggi Ilmu Pertanian Agrobisnis Perkebunan, Medan, selama selama 12 bulan mulai dari bulan Januari-Desember 2019.

Penelitian ini menggunakan Rancangan Acak Kelompok Faktorial (RAKF) dengan dua perlakuan dan tiga ulangan. Perlakuan pertama yaitu Kombinasi TKKS dan pelepah dengan 3 taraf, yaitu; $100 \%$ TKKS, 100\% Pelepah, dan $50 \%$ TKKS + $50 \%$ Pelepah. Perlakuan kedua yaitu Konsentrasi $\mathrm{NaOH}$ dan Tanin sebagai perekat dengan 3 taraf, yaitu; $\mathrm{NaOH} 40 \%$ dan Tanin $15 \mathrm{ml}, \mathrm{NaOH} 60 \%$ dan Tanin $30 \mathrm{ml}$, dan $\mathrm{NaOH} 80 \%$ dan Tanin $45 \mathrm{ml}$. Data yang diperoleh dianalisis secara statistik dengan Analysis of Variance (ANOVA) dengan uji lanjut Duncan's Multiple Range Test (DMRT) pada taraf 5\%. Data dianalisis menggunakan aplikasi Statistical Analysis Software (SAS).

Tahapan penelitian ini dilaksanakan sebagai berikut; 


\section{a. Pencucian Bahan Baku}

Bahan baku TKKS dan pelepah kelapa sawit dicuci terlebih dahulu untuk menghilangkan kotoran yang melekat. Pencucian bahan dilakukan dengan cara perendaman dalam wadah/ember, yang dilakukan sebanyak 3 kali.

b. Pencacahan Bahan Baku

Bahan baku yang telah dicuci selanjutnya dicacah agar ukurannya berikut seratnya menjadi lebih kecil berkisar 2-5 $\mathrm{cm}$. Pencacahan dapat dilakukan secara manual dengan parang atau secara mekanis dengan mesin penggiling serat. Hal ini berfungsi untuk mempermudah proses pengolahan selanjutnya.

\section{c. Perebusan Tahap I}

Setelah pencacahan bahan baku, selanjutnya dilakukan perebusan bahan baku dengan menggunakan drum kaleng berkapasitas 50 liter. Volume air yang digunakan untuk merebus $1 \mathrm{~kg}$ bahan baku adalah 5 liter. Perebusan dilakukan selama 2-3 jam dengan suhu $100^{\circ} \mathrm{C}$. Perebusan dilakukan untuk melunakkan bahan baku dan mengurangi kadar minyak yang masih terkandung di dalam bahan baku tersebut. Setelah proses perebusan selesai, bahan baku kemudian ditiriskan dalam wadah ember, selanjutnya dilanjutkan pada perebusan tahap 2 .

\section{d. Perebusan Tahap II Dan Penambahan $\mathrm{NaOH}$}

Perebusan bahan baku pada tahap 2 ini dilakukan selama $\pm 20-30$ menit dengan suhu $100^{\circ} \mathrm{C}$, serta dengan menambahkan $\mathrm{NaOH}$ sesuai dosis yang telah ditentukan. Setelah perebusan, bahan baku ditiriskan untuk mengurangi kadar air hasil dari perebusan tersebut.

\section{e. Penghalusan Bahan Baku Dan Penambahan Tanin \\ Penghalusan bahan baku} dilakukan secara manual dengan menggunakan lesung dan alu, sampai bahan baku menjadi lebih lunak/lembut untuk memudahkan proses selanjutnya. Saat proses penghalusan bahan baku ini, ditambahkan bahan perekat yaitu tanin sesuai dosis yang telah ditentukan, sehingga semua bahan menjadi homogen. Pencampuran semua bahan dilakukan secara manual yaitu dengan cara mengaduk semua bahan baku sampai merata.

\section{f. Pencetakan}

Setelah proses pencampuran bahan baku dan tanin selesai, dilanjutkan dengan memasukkan bahan campuran ke dalam cetakan biodegradable polybag. Pencetakan dilakukan secara manual dengan menggunakan pipa paralon berukuran $15 \mathrm{~cm}$, diameter 4 inchi, dan 3 inchi yang sudah dirancang untuk wadah pencetak biodegradable polybag. Pada proses pencetakan, bahan baku dimasukkan ke dalam cetakan secara perlahan-lahan sampai benar-benar merata dan padat dengan menggunakan kayu/alat bantu pemadat cetakan, supaya didapatkan hasil cetakan yang baik.

\section{g. Pengeringan}

Setelah proses pencetakan selesai, biodegradable polybag disusun di atas rak pengering untuk dikeringkan di bawah sinar matahari selama \pm 1 hari, kemudian dikering anginkan. Selanjutnya barulah dilakukan pelepasan cetakan dengan cara membuka plat luar biodegradable polybag terlebih dahulu secara 
perlahan, kemudian dikeringkan selama \pm 3 hari sampai benarbenar kering sempurna.

Parameter pengamatan pada penelitian ini adalah sifat fisika/mekanik meliputi ; Uji tekan

\section{HASIL DAN PEMBAHASAN}

Hasil penelitian menunjukkan bahwa kombinasi limbah kelapa sawit berpengaruh sangat nyata terhadap uji tekan biodegradable polybag, begitu juga dengan perlakuan dosis $\mathrm{NaOH}$ berpengaruh sangat nyata terhadap uji tekan biodegradable polybag. Interaksi biodegradable polybag $\left(\mathrm{kg} / \mathrm{cm}^{2}\right)$; Uji rendam jenuh biodegradable polybag $\left(\mathrm{kg} / \mathrm{cm}^{2}\right) ; \quad$ Uji konsistensi biodegradable polybag terhadap benturan $(\mathrm{g})$.

antara kedua perlakuan juga berpengaruh sangat nyata untuk parameter uji tekan biodegradable polybag. Data rataan parameter uji tekan biodegradable polybag terhadap kombinasi limbah kelapa sawit dan dosis $\mathrm{NaOH}$ dapat dilihat pada Tabel 1 dibawah ini : Tabel 1. Hasil Uji Beda Rataan Uji Tekan Biodegradable Polybag

\begin{tabular}{ccccc}
\hline \multirow{2}{*}{ Perlakuan N } & \multicolumn{4}{c}{ Perlakuan $\mathbf{K}$} \\
\cline { 2 - 5 } & $\mathbf{K}_{\mathbf{1}}$ & $\mathbf{K}_{\mathbf{2}}$ & $\mathbf{K}_{\mathbf{3}}$ & Rataan \\
\hline $\mathbf{N}_{\mathbf{1}}$ & $3,00 \mathrm{~d}$ & $3,02 \mathrm{c}$ & $5,00 \mathrm{a}$ & $\mathbf{3 , 6 7} \mathbf{a}$ \\
$\mathbf{N}_{\mathbf{2}}$ & $3,00 \mathrm{~d}$ & $3,00 \mathrm{~d}$ & $3,10 \mathrm{~b}$ & $\mathbf{3 , 0 3} \mathbf{b}$ \\
$\mathbf{N}_{\mathbf{3}}$ & $3,02 \mathrm{c}$ & $3,00 \mathrm{~d}$ & $3,00 \mathrm{~d}$ & $\mathbf{3 , 0 1} \mathbf{~ c}$ \\
\hline Rataan & $\mathbf{3 , 0 1 b}$ & $\mathbf{3 , 0 1 b}$ & $\mathbf{3 , 7 0} \mathbf{~ a}$ & $\mathbf{2 9 , 1 4}$
\end{tabular}

Keterangan : Angka-angka yang diikuti oleh huruf kecil yang tidak sama pada kolom yang sama menunjukkan berbeda nyata menurut uji Duncan pada taraf uji 5\%

Tabel 1 menunjukkan bahwa perlakuan kombinasi limbah kelapa sawit yang tertinggi terdapat pada perlakuan $\mathrm{K}_{3}$ yaitu $50 \%$ TKKS + $50 \%$ pelepah kelapa sawit. Uji tekan biodegradable polybag organik pada perlakuan $\mathrm{K}_{3}$ adalah $3,70 \mathrm{~kg} / \mathrm{cm}^{2}$. Sedangkan kombinasi limbah kelapa sawit yang terendah terdapat pada perlakuan $\mathrm{K}_{1}$ dan $\mathrm{K}_{2}$ yaitu $(100 \%$ TKKS) dan (100\% pelepah kelapa sawit). Uji tekan biodegradable polybag organik pada perlakuan $\mathrm{K}_{1}$ dan $\mathrm{K}_{2}$ adalah $3,01 \mathrm{~kg} / \mathrm{cm}^{2}$.

Perlakuan dosis $\mathrm{NaOH}$ yang tertinggi terdapat pada perlakuan $\mathrm{N}_{1}$ yaitu $40 \% \mathrm{NaOH}$ dan tanin $15 \mathrm{ml}$. Uji tekan biodegradable polybag organik pada perlakuan $\mathrm{N}_{1}$ adalah $3,67 \mathrm{~kg} / \mathrm{cm}^{2}$. Sedangkan dosis $\mathrm{NaOH}$ yang terendah terdapat pada perlakuan $\mathrm{N}_{3}$ yaitu $80 \% \mathrm{NaOH}$ dan tanin $45 \mathrm{ml}$. Uji tekan biodegradable polybag organik pada perlakuan $\mathrm{N}_{3}$ adalah $3,01 \mathrm{~kg} / \mathrm{cm}^{2}$.

Interaksi antara perlakuan kombinasi limbah kelapa sawit dan dosis $\mathrm{NaOH}$ yang tertinggi terdapat pada perlakuan $\mathrm{K}_{3} \mathrm{~N}_{1}$ yaitu $(50 \%$ TKKS $+50 \%$ pelepah kelapa sawit dengan $40 \% \mathrm{NaOH}$ dan tanin $15 \mathrm{ml}$ ). Uji tekan biodegradable polybag organik pada perlakuan $\mathrm{K}_{3} \mathrm{~N}_{1}$ adalah $5,00 \mathrm{~kg} / \mathrm{cm}^{2}$. Sedangkan kombinasi limbah kelapa sawit dan dosis $\mathrm{NaOH}$ yang terendah terdapat pada 5 perlakuan yaitu $\mathrm{K}_{1} \mathrm{~N}_{1}, \mathrm{~K}_{1} \mathrm{~N}_{2}, \mathrm{~K}_{2} \mathrm{~N}_{2}$, $\mathrm{K}_{2} \mathrm{~N}_{3}$, dan $\mathrm{K}_{3} \mathrm{~N}_{3}$. Kelima perlakuan itu adalah (100\% TKKS dengan 40\% $\mathrm{NaOH}$ dan tanin $15 \mathrm{ml}),(100 \%$ TKKS dengan $60 \% \mathrm{NaOH}$ dan tanin $30 \mathrm{ml}),(50 \%$ TKKS $+50 \%$ pelepah 
kelapa sawit dengan $60 \% \mathrm{NaOH}$ dan $\operatorname{tanin} 30 \mathrm{ml}),(50 \%$ TKKS $+50 \%$ pelepah kelapa sawit dengan $80 \%$ $\mathrm{NaOH}$ dan tanin $45 \mathrm{ml})$, dan $(100 \%$ pelepah kelapa sawit dengan $80 \%$ $\mathrm{NaOH}$ dan tanin $45 \mathrm{ml}$ ). Uji tekan biodegradable polybag organik pada kelima perlakuan tersebut adalah $3,00 \mathrm{~kg} / \mathrm{cm}^{2}$. Hubungan antara kombinasi limbah kelapa sawit dan dosis $\mathrm{NaOH}$ dapat dilihat seperti gambar dibawah ini :

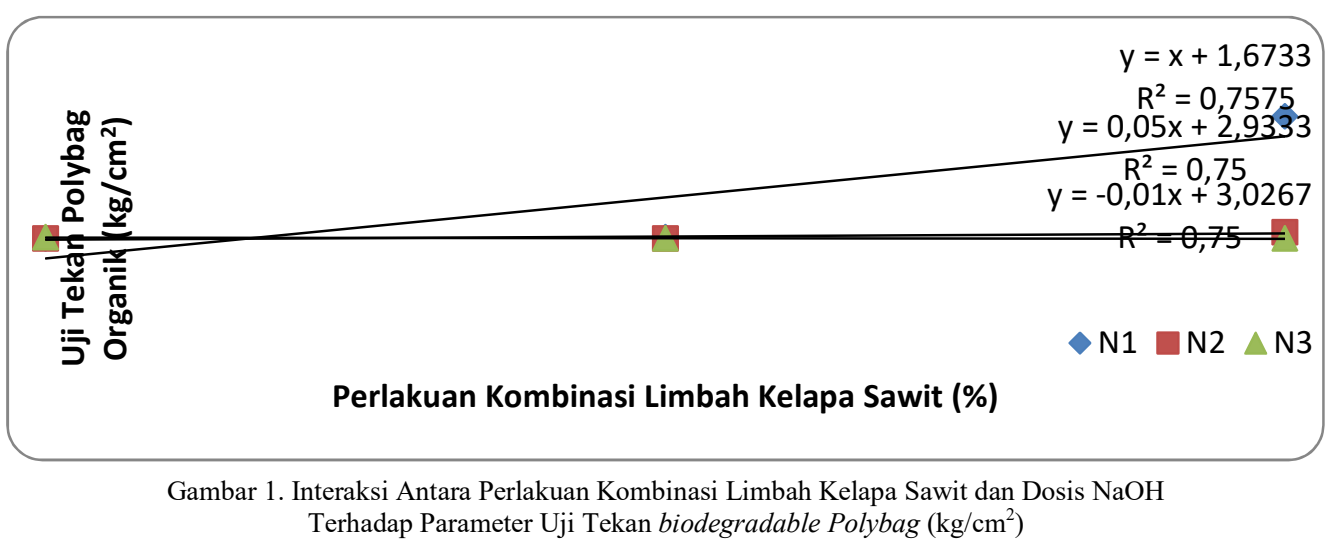

Dari Gambar 1 dapat diketahui bahwa uji tekan biodegradable polybag yang terbaik terdapat pada perlakuan $\mathrm{K}_{3} \mathrm{~N}_{1}$ yaitu $(50 \%$ TKKS + $50 \%$ pelepah kelapa sawit dengan $40 \% \mathrm{NaOH}$ dan tanin $15 \mathrm{ml}$. Kuat

tarik adalah parameter penting yang berpengaruh terhadap sifat mekanik pot tanam organik. Kuat tarik merupakan gaya tarik maksimum yang dapat ditahan oleh pot tanam organik. Uji kuat tarik dalam penelitian ini menggunakan UTM (Universal Testing Machine) sebagai alat. Dalam pengujian kuat tarik ini dibutuhkan beberapa nilai dimensi yang dimiliki oleh sampel pelepah pisang yang dimiliki, yaitu dimensi lebar, tebal dan panjang. Suhu pada saat pengeringan dan lebar pita pelepah pisang berpengaruh terhadap kuat tarik yang dimiliki oleh pelepah pisang yang merupakah bahan utama pot tanam organik. Hal ini didukung oleh I Putu et al. (2010), yang menyatakan temperatur terendah ikatan antara matrik dan penguat menjadi lemah karena adanya uap air yang meresap pada serat dapat merusak serat tersebut sehingga terjadi delaminasi. Menurut Utomo et.al (2013) yang melakukan penelitan tentang kuat tarik plastik biodegradable, besarnya kuat tarik juga dipengaruhi oleh parameter ketebalan. Perbandingan ketebalan dalam satu variabel suhu diperoleh dari hubungan variabel ketebalan yang berbanding terbalik dengan kuat tarik plastik.

Perlakuan kombinasi limbah kelapa sawit juga menunjukkan pengaruh sangat nyata terhadap uji rendam jenuh biodegradable polybag, begitu juga dengan perlakuan dosis $\mathrm{NaOH}$ berpengaruh sangat nyata terhadap uji rendam jenuh biodegradable polybag. Interaksi antara kedua perlakuan juga berpengaruh sangat nyata untuk parameter uji rendam jenuh biodegradable polybag. Data rataan parameter uji rendam biodegradable polybag terhadap kombinasi limbah kelapa sawit dan dosis $\mathrm{NaOH}$ dapat dilihat pada Tabel 2 di bawah ini: 
Tabel 2. Hasil Uji Beda Rataan Uji Rendam Jenuh Biodegradable Polybag

\begin{tabular}{ccccc}
\hline \multirow{2}{*}{ Perlakuan N } & \multicolumn{4}{c}{ Perlakuan $\mathbf{~}$} \\
\cline { 2 - 5 } & $\mathbf{K}_{\mathbf{1}}$ & $\mathbf{K}_{\mathbf{2}}$ & $\mathbf{K}_{\mathbf{3}}$ & Rataan \\
\hline $\mathbf{N}_{\mathbf{1}}$ & $600,00 \mathrm{~b}$ & $720,33 \mathrm{~d}$ & $740,33 \mathrm{e}$ & $\mathbf{6 8 6 , 8 9} \mathbf{b}$ \\
$\mathbf{N}_{\mathbf{2}}$ & $680,00 \mathrm{c}$ & $680,00 \mathrm{c}$ & $740,00 \mathrm{e}$ & $\mathbf{7 0 0 , 0 0 ~ c}$ \\
$\mathbf{N}_{\mathbf{3}}$ & $660,00 \mathrm{c}$ & $760,00 \mathrm{f}$ & $560,00 \mathrm{a}$ & $\mathbf{6 6 0 , 0 0} \mathbf{a}$ \\
\hline Rataan & $\mathbf{6 4 6 , 6 7} \mathbf{a}$ & $\mathbf{7 2 0 , 1 1 c}$ & $\mathbf{6 8 0 , 1 1 ~ b}$ & $\mathbf{6 1 4 0 , 6 6}$ \\
\hline
\end{tabular}

Keterangan: Angka-angka yang diikuti oleh huruf kecil yang tidak sama pada kolom yang sama menunjukkan berbeda nyata menurut uji Duncan pada taraf uji 5\%

Pada Tabel 2 diperlihatkan bahwa kombinasi limbah kelapa sawit yang tertinggi terdapat pada perlakuan $\mathrm{K}_{3}$ yaitu $50 \%$ TKKS $+50 \%$ pelepah kelapa sawit. Uji rendam jenuh biodegradable polybag organik pada perlakuan $\mathrm{K}_{3}$ adalah 560,00 gram. Sedangkan nilai terendah terdapat pada perlakuan $\mathrm{K}_{2}$ yaitu $100 \%$ pelepah kelapa sawit. Uji rendam jenuh biodegradable polybag organik pada perlakuan $\mathrm{K}_{2}$ adalah 760,00 gram.

Perlakuan dosis $\mathrm{NaOH}$ yang tertinggi terdapat pada perlakuan $\mathrm{N}_{3}$ yaitu $80 \% \mathrm{NaOH}$ dan tanin $45 \mathrm{ml}$. Uji rendam jenuh biodegradable polybag organik pada perlakuan $\mathrm{N}_{3}$ adalah 660,00 gram. Sedangkan dosis $\mathrm{NaOH}$ yang terendah terdapat pada perlakuan $\mathrm{N}_{2}$ yaitu $60 \% \mathrm{NaOH}$ dan tanin $30 \mathrm{ml}$. Uji rendam jenuh biodegradable polybag organik pada perlakuan $\mathrm{N}_{3}$ adalah 700,00 gram.

Interaksi antara kombinasi limbah kelapa sawit dan dosis $\mathrm{NaOH}$ tertinggi terdapat pada perlakuan $\mathrm{K}_{3} \mathrm{~N}_{3} \quad$ yaitu $\quad(50 \% \quad$ TKKS $+50 \%)$ pelepah kelapa sawit dengan $80 \%$ $\mathrm{NaOH}$ dan tanin $45 \mathrm{ml}$ ). Uji rendam jenuh biodegradable polybag organik pada perlakuan $\mathrm{K}_{2} \mathrm{~N}_{3}$ adalah 560,00 gram. Sedangkan kombinasi limbah kelapa sawit dan dosis $\mathrm{NaOH}$ yang terendah terdapat pada perlakuan $\mathrm{K}_{2} \mathrm{~N}_{3}$ yaitu (100\% pelepah kelapa sawit dengan $80 \% \mathrm{NaOH}$ dan tanin $45 \mathrm{ml}$ ). Uji rendam jenuh biodegradable polybag organik pada perlakuan $\mathrm{K}_{2} \mathrm{~N}_{3}$ adalah 760,00 gr. Hubungan antara kombinasi limbah kelapa sawit dan dosis $\mathrm{NaOH}$ dapat dilihat seperti gambar dibawah ini:

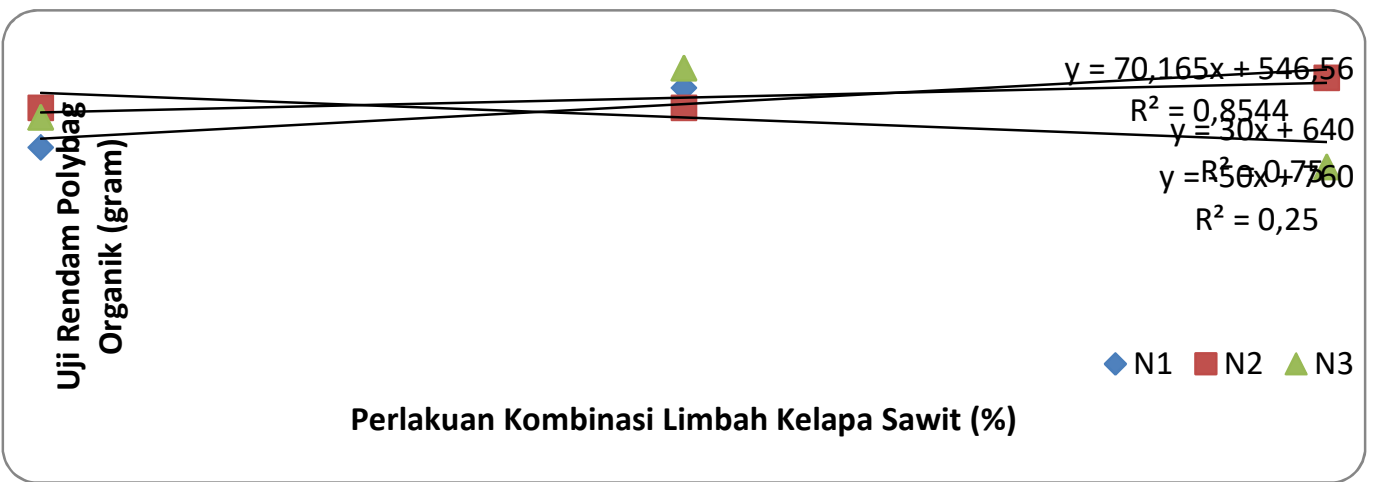

Gambar 2. Interaksi Antara Perlakuan Kombinasi Limbah Kelapa Sawit dan Dosis NaOH Terhadap Parameter Uji Rendam Jenuh Biodegradable Polybag (Gram) 
Dari Gambar 2 dapat diketahui uji rendam biodegradable polybag diperoleh dengan membandingkan berat sebelum dan sesudah biodegradable polybag yang direndam di dalam air. Uji rendam jenuh perlu dilakukan untuk mengetahui tingkat ketahanan biodegradable polybag ketika diaplikasikan di lapangan. Hasil uji daya serap air tertinggi terdapat pada perlakuan $\mathrm{K}_{3} \mathrm{~N}_{3}(560,00 \mathrm{~g})$, sementara yang terendah terdapat pada $\mathrm{K}_{2} \mathrm{~N}_{3}$ $(760,00 \mathrm{~g})$. Hal ini dikarenakan perekat mempermudah penutupan rongga kapiler, sehingga air tidak mudah terserap oleh pot organik (Roza, 2009).

Biodegradable polybag
merupakan suatu bahan yang memiliki sifat menyerap air dan uap. Sebaliknya, apabila udara di sekitarnya menjadi kering, maka biodegradable polybag akan kehilangan air sampai kembali mencapai keseimbangan. Faktorfaktor yang mempengaruhi tinggi rendahnya penyerapan air biodegradable polybag adalah adanya saluran kapiler yang menghubungkan antara ruang kosong, volume ruang kosong diantar pot, luas permukaan pot yang tidak ditutupi perekat (Roza, 2009). Tingginya daya serap air biodegradable polybag terjadi karena Tabel 3. Hasil Uji Beda Rataan Uji Kons ketahanan perekat terhadap air yang kurang baik. Biodegradable polybag organik yang daya serap airnya tinggi memiliki ketahanan yang rendah, sedangkan biodegradable polybag yang daya serap airnya rendah memiliki ketahanan yang cukup baik, sehingga dapat diaplikasikan diluar maupun di dalam ruangan.

Jenis dan komposisi perekat memberi pengaruh tersendiri terhadap kualitas wadah semai (Budi et al., 2012). Jumlah kadar air yang terdapat pada bahan juga dapat mempengaruhi perubahan dan penguraian yang terjadi pada wadah semai (Widarti et al., 2015).

Perlakuan kombinasi limbah kelapa sawit juga menunjukkan pengaruh sangat nyata terhadap uji konsistensi biodegradable polybag terhadap benturan, begitu juga dengan perlakuan dosis $\mathrm{NaOH}$ berpengaruh sangat nyata terhadap uji konsistensi biodegradable polybag terhadap benturan. Interaksi antara kedua perlakuan juga berpengaruh sangat nyata untuk parameter uji konsistensi biodegradable polybag terhadap benturan. Data rataan parameter uji konsistensi biodegradable polybag terhadap kombinasi limbah kelapa sawit dan dosis $\mathrm{NaOH}$ dapat dilihat pada Tabel 3 di bawah ini:

\begin{tabular}{ccccc}
\hline \multirow{2}{*}{ Perlakuan $\mathbf{N}$} & \multicolumn{4}{c}{ Perlakuan $\mathbf{~}$} \\
\cline { 2 - 5 } & $\mathbf{K}_{\mathbf{1}}$ & $\mathbf{K}_{\mathbf{2}}$ & $\mathbf{K}_{\mathbf{3}}$ & Rataan \\
\hline $\mathbf{N}_{\mathbf{1}}$ & $160,33 \mathrm{e}$ & $210,00 \mathrm{~b}$ & $210,00 \mathrm{~b}$ & $\mathbf{1 9 3 , 4 4} \mathbf{b}$ \\
$\mathbf{N}_{\mathbf{2}}$ & $199,00 \mathrm{c}$ & $199,00 \mathrm{c}$ & $166,67 \mathrm{~d}$ & $\mathbf{1 8 8 , 2 2} \mathbf{c}$ \\
$\mathbf{N}_{\mathbf{3}}$ & $230,33 \mathrm{a}$ & $210,00 \mathrm{~b}$ & $210,00 \mathrm{~b}$ & $\mathbf{2 1 6 , 7 8} \mathbf{a}$ \\
\hline Rataan & $\mathbf{1 9 6 , 5 5} \mathbf{b}$ & $\mathbf{2 0 6 , 3 3} \mathbf{a}$ & $\mathbf{1 9 5 , 5 6} \mathbf{c}$ & $\mathbf{1 7 9 5 , 3 3}$
\end{tabular}

Keterangan : Angka-angka yang diikuti oleh huruf kecil yang tidak sama pada kolom yang sama menunjukkan berbeda nyata menurut uji Duncan pada taraf uji 5\% 
Tabel 3 menunjukkan bahwa perlakuan kombinasi limbah kelapa sawit yang tertinggi terdapat pada perlakuan $\mathrm{K}_{2}$ yaitu $100 \%$ pelepah kelapa sawit. Uji konistensi biodegradable polybag pada perlakuan $\mathrm{K}_{2}$ adalah 206,33 gr. Sedangkan kombinasi limbah kelapa sawit yang terendah terdapat pada perlakuan $\mathrm{K}_{3}$ yaitu $(50 \%$ TKKS + $50 \%$ pelepah kelapa sawit). Uji konsistensi biodegradable polybag organik pada perlakuan $\mathrm{K}_{3}$ adalah 195,56 gr.

Perlakuan dosis $\mathrm{NaOH}$ yang tertinggi terdapat pada perlakuan $\mathrm{N}_{3}$ yaitu $80 \% \mathrm{NaOH}$ dan tanin $45 \mathrm{ml}$. Uji konsistensi biodegradable polybag organik pada perlakuan $\mathrm{N}_{3}$ adalah 216,78g. Sedangkan dosis $\mathrm{NaOH}$ yang terendah terdapat pada perlakuan $\mathrm{N}_{2}$ yaitu $60 \% \mathrm{NaOH}$ dan tanin $30 \mathrm{ml}$. Uji konsistensi biodegradable polybag organik pada perlakuan $\mathrm{N}_{2}$ adalah 188,22 gr.

Interaksi antara kombinasi limbah kelapa sawit dan dosis $\mathrm{NaOH}$ yang tertinggi terdapat pada perlakuan $\mathrm{K}_{1} \mathrm{~N}_{3}$ yaitu (100\% TKKS dengan $80 \% \mathrm{NaOH}$ dan tanin $45 \mathrm{ml}$ ). Uji konsistensi biodegradable polybag organik pada perlakuan $\mathrm{K}_{1} \mathrm{~N}_{3}$ adalah 230,33 gr. Sedangkan kombinasi limbah kelapa sawit dan dosis $\mathrm{NaOH}$ yang terendah terdapat pada perlakuan $\mathrm{K}_{1} \mathrm{~N}_{1}$ yaitu $(100 \%$ TKKS dengan $40 \% \mathrm{NaOH}$ dan tanin $15 \mathrm{ml})$. Hasil uji konsistensi biodegradable polybag organik pada perlakuan $\mathrm{K}_{1} \mathrm{~N}_{1}$ adalah 160,33g. Hubungan antara kombinasi limbah kelapa sawit dan dosis $\mathrm{NaOH}$ dapat dilihat seperti pada Gambar 3:

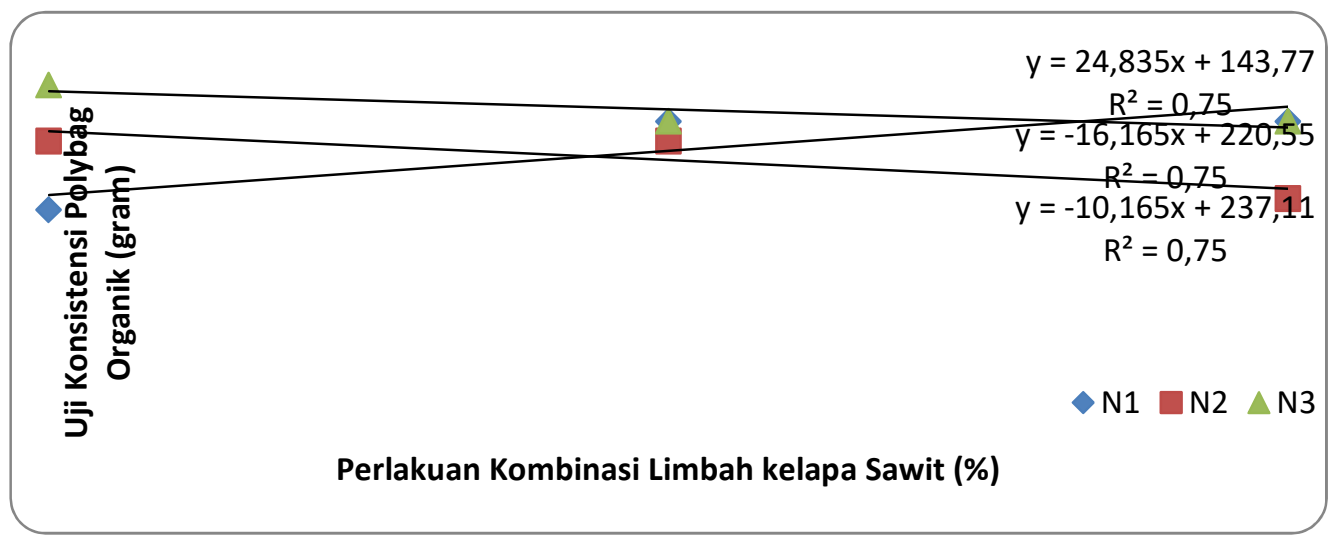

Gambar 3. Interaksi Antara Perlakuan Kombinasi Limbah Kelapa Sawit dan Dosis $\mathrm{NaOH}$ Terhadap Parameter Uji Konsistensi Biodegradable Polybag Terhadap Benturan (Gram)

Dari Gambar 3 dapat diketahui bahwa uji konsistensi biodegradable polybag terhadap benturan yang terbaik terdapat pada perlakuan $\mathrm{K}_{1} \mathrm{~N}_{3}$ yaitu (100\% TKKS dengan $80 \%$ $\mathrm{NaOH}$ dan tanin $45 \mathrm{ml}$ ). Hal ini dikarenakan limbah kelapa sawit menghasilkan serat yang kuat dan panjang yang dapat digunakan untuk membuat biodegradable polybag. Tandan kosong kelapa sawit menghasilkan serat yang kuat yang dapat digunakan untuk membuat biodegradable polybag. Menurut Sutrisno \& Wahyudi (2012), bahwa serat kelapa sawit dapat diperoleh dengan mengepresnya sehingga keluar air, minyak, dan kotoran yang terkandung didalamnya. Selanjutnya TKKS tersebut diuraikan dengan mesin pengurai serat. Selain serat yang kuat dan panjang, limbah 
kelapa sawit yang digunakan mempunyai daya tenun yang tinggi sehingga biodegradable polybag yang dihasilkan akan lebih kuat. Menurut (Eko \& Agus, 2012) dalam (Silalahi, 2017) bahwa kualitas serat tandan kelapa sawit mempunyai nilai daya tenun yang tinggi yaitu $72,98 / 50$. Serat pelepah kelapa sawit lebih panjang dari serat tandan kosong kelapa sawit (Kamaliah, 2016).

$\begin{array}{rr}\text { Dalam } & \text { pembuatan } \\ \text { biodegradable } & \text { polybag }\end{array}$
menggunakan bahan kimia $\mathrm{NaOH}$ untuk menghancurkan senyawa lignin dan selulosa yang ada pada bahan yang digunakan. Penggunaan $\mathrm{NaOH}$ dikarenakan mudah didapat, harga murah dan lebih cepat bereaksi dengan lignin. Asep et al. (2017), menyatakan penambahan caustic soda berfungsi untuk melarutkan khlorinat lignin dan zat ekstraktif

\section{SIMPULAN}

1. Kombinasi limbah padat kelapa sawit (TKKS dan pelepah) menunjukkan pengaruh yang nyata terhadap uji kualitas biodegradable polybag pada semua parameter pengamatan dengan nilai terbaik masingmasing pengamatan yaitu uji tekan polybag $\left(3,70 \mathrm{~kg} / \mathrm{cm}^{2}\right)$ pada perlakuan $\mathrm{K}_{3}$, uji rendam jenuh polybag $(646,67 \mathrm{~g})$ pada perlakuan $\mathrm{K}_{1}$, uji konsistensi polybag (206,33g) pada perlakuan $\mathrm{K}_{2}$.

2. Perlakuan kombinasi $\mathrm{NaOH}$ dan tanin juga menunjukkan pengaruh yang nyata terhadap uji kualitas biodegradable polybag pada semua parameter dengan nilai terbaik masingmasing yaitu uji tekan polybag $\left(3,67 \mathrm{~kg} / \mathrm{cm}^{2}\right)$ pada perlakuan lainnya yang terdapat dalam bahan baku sehingga serat selulosa terlepas dari ikatannya.

Menurut (Sumada, Tamara, \& Fiqih, 2011) dalam (Harry et al., 2016) delignifikasi bertujuan untuk mengurangi kadar lignin di dalam bahan berlignoselulosa. Delignifikasi akan membuka struktur lignoselulosa agar selulosa menjadi lebih mudah diakses. Proses delignifikasi akan melarutkan kandungan lignin di dalam bahan sehingga mempermudah proses pemisahan lignin dengan serat. Pada beberapa penelitian, delignifikasi umumnya menggunakan $\mathrm{NaOH}$ dan $\mathrm{H}_{2} \mathrm{SO}_{4}$. Selanjutnya (Anwardah , 2016) dalam (Silalahi, 2017) menambahkan campuran antara Natrium Sulfide dan Natrium Hidroksida diperlukan untuk menghilangkan kandungan lignin yang tidak diinginkan pada bahan seperti kayu.

$\mathrm{N}_{1}$, uji rendam jenuh polybag $(600,00 \mathrm{~g})$ pada perlakuan $\mathrm{N}_{3}$, uji konsistensi polybag $(216,78$ gr) pada perlakuan $\mathrm{N}_{3}$.

3. Interaksi perlakuan antara kombinasi limbah padat kelapa sawit (TKKS dan pelepah) dengan kombinasi $\mathrm{NaOH}$ dan tanin juga menunjukkan pengaruh yang nyata terhadap uji kualitas biodegradable polybag pada semua parameter pengamatan dengan nilai terbaik masing - masing pengamatan yaitu uji tekan polybag $(5,00$ $\mathrm{kg} / \mathrm{cm}^{2}$ ) pada perlakuan $\mathrm{K}_{3} \mathrm{~N}_{1}$, uji rendam jenuh polybag $(560,00$ gr) pada perlakuan $\mathrm{K}_{3} \mathrm{~N}_{3}$, uji konsistensi polybag $(230,33$ gr $)$ pada perlakuan $\mathrm{K}_{1} \mathrm{~N}_{3}$. 


\section{SARAN}

Sebaiknya dilakukan penelitian lanjutan dengan mengaplikasikan biodegradable polybag pada beberapa jenis tanaman ataupun media tanam yang berbeda.

\section{DAFTAR PUSTAKA}

Asep Hermawan, Farah Diba, Yeni Mariani, Dina Setyawati, Nurhaida. 2017. Sifat Kimia Batang Kelapa Sawit (Elaeis Guinensis Jacq) Berdasarkan Letak Ketinggian Dan Kedalaman Batang. Chemical Properties of Oil Palm Trunk (Elaeis guinensis Jacq) Based on Height and Depth of Trunk. Fakultas Kehutanan Universitas Tanjungpura Pontianak.

Budi, S.W, Andi Sukendro, dan Lina Karlinasari. 2012. Penggunaan Pot Berbahan Dasar Organik Untuk Pembibitan Gmelina arborea Roxb. Seedling Production In The Nursery. Instittut Pertanian Bogor. Bogor-Indonesia.

Harry Rizka Permatasari, Fakhili Gulo, Bety Lesmini. 2016. Pengaruh Konsentrasi $\mathrm{H}_{2} \mathrm{SO}_{4}$ Dan $\mathrm{NaOH}$ Terhadap Delignifikasi Serbuk Bambu (Gigantochloa apus). Program Studi Pendidikan Kimia FKIP. Universitas Sriwijaya. Palembang.

Joko Prayitno Susanto, Arif Dwi Santoso dan Nawa Suwedi. 2017. Perhitungan Potensi Limbah Padat Kelapa Sawit Untuk Sumber Energi Terbaharukan Dengan Metode LCA. Jurnal Teknologi Lingkungan Vol. 18, No 2, Juli 2017, 165-172.
Kamaliah, 2016. Pengaruh Umur Tanaman dan Posisi Pelepah Kelapa Sawit Terhadap Komponen Kimia Tanaman Kelapa Sawit (Elaeis guineensis Jacq.). Jurnal Media Ilmiah Teknik Lingkungan.1: 22-28.

Lokantara, I Putu; Suardana, Ngakan Putu Gede; Karohika, I Made Gatot; Nanda. 2010. Pengaruh Panjang Serat Pada Temperatur Uji Yang Berbeda Terhadap Kekuatan Tarik Komposit Polyester Serat Tapis Kelapa. Jurnal Ilmiah Teknik Mesin Vol. 4 No. 2 (166-172).Universitas Udayana Roza, I., (2009), Pengaruh Perbedaan Proses Penyediaan Serat dengan Cara Mekanis Limbah Tandan Kosong Sawit terhadap Papan Serat, Sainstek, 12(1), 917.

Silalahi, $\quad$ Kristofel. 2017. Perancangan Green Polybag Dari Beberapa Macam Limbah Kelapa Sawit (TKKS, Pelepah, dan Batang Dalam Kelapa Sawit) Dengan Bahan Campuran Kertas Koran Sebagai Media Pembibitan Pre Nursery. Tugas Akhir. Program Studi Budidaya Perkebunan, STIPAP. Medan. Sutrisno, E, dan Wahyudi, A. 2012. Karakteristik Pot Organik Berbahan Dasar Limbah Perkebunan Kelapa Sawit. Riau. Balai Penelitian Teknologi Serat Tanaman Hutan.

Utomo, A. W., B. D. Argo, dan M. B. Hermanto. 2013. Pengaruh Suhu dan Lama Pengeringan terhadap Karakteristik Fisikokimiawi Plastik Biodegradable dari Komposit 
pati Lidah Buaya (Aloe Vera) -

Kitosan. Jurnal Bioproses

Komoditas Tropis.

Widarti, B. N., Wardhini, W. K., \&

Sarwono, E., (2015), Pengaruh

rasio $\mathrm{C} / \mathrm{N}$ bahan baku pada

pembuatan kompos dari kubis

dan kulit pisang, Jurnal

Integrasi Proses, 5(2). 